\title{
Liquid Crystals: A Bridge Between Science and Technology
}

As volunteers for ALCOM Education Outreach, the education program of the National Science Foundation's Science and Technology Center for Advanced Liquid Crystalline Optical Materials (ALCOM), we take advantage of the spectacular optical and electrooptical properties of liquid crystals to teach basic principles of optics to students from kindergarten to beginning college.

Normally, students are taught predominantly about the three phases of matter-solid, liquid, and gas-but plas$\mathrm{ma}$ and liquid crystals are often overlooked or omitted entirely. Some students are already aware of the existence of liquid crystals because they are familiar with the acronym LCD (liquid crystal display) which they associate with computer games, laptop computers, small televisions, and appliances that use LCDs to display information. Our science education program uses LCDs to teach basic scientific principles and to demonstrate the bond between science and technology. Understanding the underlying physical principles of the LCD requires basic concepts from physics, chemistry, and engineering, so liquid crystals are ideal materials to show the link between the various scientific disciplines.

The main components of our program include hands-on workshops for students, four-week summer workshops for high school science teachers, and a newsletter that is distributed to physics educators (predominantly high school physics teachers) nationwide.

For the students, perhaps the most exciting part of the program is the chance to fabricate their own LCDs from scratch. The twisted nematic display most commonly used in digital wristwatches, calculators, and small electronic devices incorporates two polarizers, two specially treated conducting glass substrates, a nematic liquid crystal, spacers to control the thickness of the display, and epoxy glue. The students construct their own displays with a little guidance and some "subliminal" messages of basic scientific importance. They can then test their displays, applying an electric field to see if a display switches from transparent to black and observing the transmission of a flashlight (or laser) shining through the cell. The students also demonstrate the rotation of polarization of light; by heating their display into the liquid phase and viewing it between crossed polarizers as it cools to the liquid crystal phase, they can optically observe a phase transition. Many students relate the concept of polarization to their sunglasses.

The next display the students construct, known as the polymer-dispersed liquid crystal display (PDLC), operates on the principle of electrically controlled light scattering. Micrometer-sized liquid crystal droplets are dispersed in a polymer matrix sandwiched between conducting glass plates. The PDLC display switches from opaque white to crystal

clear upon application of an electric field. The students dabble in a little polymer chemistry by measuring out small amounts of liquid crystal, prepolymer, and curing agent. After mixing these components and sandwiching the mixture between conducting glass substrates, the students cure their displays in the oven. After 30 minutes, the displays are ready, and the students get a thrill from switching their electrically controllable window.

Chemistry and physics go hand-inhand in many of today's research projects, and constructing a PDLC display enables students to link various scientific disciplines to technology. The students really appreciate working with materials that are so new and that are just coming into the commercial market in the form of switchable windows for privacy and solar control.

More importantly, the PDLC can be related to many everyday occurrences in which light scattering is the underlying physical principle, such as white clouds, the blue sky, and the different translucence of skim milk versus whole milk. A middle school student who had participated in one of the workshops wrote to us because he wanted to construct a refrigerator with a switchable door so that his mother wouldn't get mad at him any more for "refrigerating the neighborhood" while he debated (with the

At the conclusion of the workshops, the students get down and dirty to model the long, thin nature of most liquid crys. tal molecules. In the nematic phase, the simplest liquid crystal phase, the elongated molecules, on average, lie along a common direction (orientational order) but lack the positional order of crystals. In the smectic A phase, the molecules are arranged in layers along a common direction, and in the smectic C phase modeled here by the students, the molecules in the planes have a tilt angle. At first glance this may seem to be a somewhat silly exercise, but after this the students have a much deeper understanding of the differences between orientational and positional order, and how the degree of order is used to define various phases of matter. door open) what to have for a snack. A first grader asked if these windows could be used in the President's limousine.

In the summer workshops for high school science teachers, the teachers attend lectures on the basic chemistry and physics of liquid crystals. During the first week, they speak with scientists in the liquid crystal field at the Liquid Crystal Institute at Kent State University. To become proficient at fabricating LCDs, the following week they perform many of the same experiments that are done in the student workshops. The teachers make several of each type of display and focus on how they can use these materials in their classrooms to demonstrate many of the principles mentioned here. During the next two weeks, they work independently in the labs of the 
Liquid Crystal Institute, where they have access to the scientific instrumentation and materials and where they also have help from liquid crystal scientists. Within these two weeks they will develop several novel experiments that are suitable for high school classroom demonstrations and student laboratory courses. Their final reports on experiments and demonstrations are incorporated into a bimonthly newsletter that reaches many science educators from high schools as well as colleges and universities.

Each newsletter focuses on different physical concepts, contains detailed descriptions of classroom demonstrations and experiments, and is accompanied by the materials (such as polarizers, liquid crystal cells, $1 / 4$ wave plates, etc.) needed to perform the described demonstrations. The experiments developed by the teachers in the summer workshops are incorporated into these newsletters, and contributions from other educators and students are always appreciated. For more information on the ALCOM Education Outreach program contact: ALCOM Education Outreach, Liquid

The Education Exchange highlights the experiences of scientists and engineers with local schools, along with helpful hints and resources. If you would like to share your own involvement in science education, contact: Finley Shapiro, Department of Electrical and Computer Engineering, Drexel University, Philadelphia, PA 19104, U.S.A. Phone (215) 895-6749; fax (215) 895-1695; e-mail: shapiro@ece.drexel.edu
Crystal Institute, Kent State University, Kent, Ohio 44242-0001 or the authors, Renate J. Ondris-Crawford (e-mail crawford@chem.nrl.navy.mil) and Gregory P. Crawford (e-mail: crawford 2@chem.nrl. navy.mil).

Renate J. Ondris-Crawford and Gregory P. Crawford are co-editors of the ALCOM Education Outreach (AEO) newsletter. They are currently National Research Council Postdoctoral Fellows at the Naval Research Laboratory in Washington, $D C$, and $A E O$ Ambassadors in the Washington, DC metropolitan area.

To receive additional information on how you can get involved in enhancing $\mathrm{K}-12$ science education, circle number 120 on the Reader Service Card.

\section{MRS Fall Meeting Registration . . Call (412) 367-3004, ext. 310}

\section{For the foremost books in microscopy, turn to Plenum Press.}

\section{ELECTRON}

\section{MICRODIFFRACTION}

by J.C.H. Spence and J.M. Zuo

Features recent theoretical and experimental developments in the field, detailing current advances in the applications of the transmission electron microscope. Thoroughly discusses spacegroup determination by CBED, structure factor measurement by CBED, coherent CBED from defects using subnanometer probes, and strain measurement using HOLZ line shifts. Also covers $\bullet$ historical aspects of the field $\bullet$ basic principles - current progress in applications, experimental techniques, computer algorithms, and instrumentation. 0-306-44262-0/382 pp./ill./1992/\$49.50

\begin{abstract}
MICROANALYSIS OF SOLIDS edited by B. G. Yacobi, D. B. Holt, and L. L. Kazmerski

A comprehensive and systematic description of the basic principles of the most widely used techniques for the analysis of the physical, structural, and compositional properties of solids with a spatial resolution of approximately $1 \mu \mathrm{m}$ or less. Groups the techniques according to the means of excitation, covering electron beam techniques $\bullet$ ion beam techniques - photon beam techniques • acoustic wave excitation $\bullet$ tunneling of electrons and scanning probe microscopies. Discusses fundamentals, instrumentation, methodologies, applications, and examples of current and emerging techniques.
\end{abstract}

0-306-44433-X/474 pp./ill./1994/\$95.00

\section{New updated edition of a popular text! \\ INTRODUCTION TO MICROSCOPY BY MEANS OF LIGHT, ELECTRONS, X-RAYS, OR ACOUSTICS Second Edition by Theodore George Rochow and Paul Arthur Tucker \\ From reviews of the First Edition: "The authors describe the many aspects of microscopy in a very well-organized and easily followed format. . . I I can thoroughly recommend this book." \\ - Journal of Modern Optics (formerly Optica Acta)}

"A thought-stimulating book, with a fresh approach to many familiar topics, and one that can be recommended for general reading."

0-306-44684-7/436 pp. + index/ill. $1994 / \$ 49.50$

Book prices are $20 \%$ higher outside US \& Canada.
MUBLISHING CORPORATION

233 Spring Street, New York, NY 10013-1578

Telephone orders: $212-620-8000 / 1-800-221-9369$

Circle No. 22 on Reader Service Card. 